\title{
PEMBERDAYAAN SISWA BERKEBUTUHAN KHUSUS MELALUI KETERAMPILAN UNTUK MELATIH KEMANDIRIAN DI SLB PSM TAKERAN - MAGETAN
}

\author{
Tatik Mulyati ${ }^{1}$, Saraswati Budi Utami ${ }^{2}$, Hendro Susilo ${ }^{3}$ \\ ${ }^{1,2)}$ Program Studi Manajemen, Fakultas Ekonomi \\ ${ }^{3}$ Program Studi Teknik Sipil, Fakultas Teknik \\ Universitas Merdeka Madiun \\ Email: tatikmulyati@ unmer-madiun.ac.id
}

\begin{abstract}
Students at the Extra Ordinary School of Pesantren SabililMuttaqien (SLB PSM) Takeran Magetan Regency are dominated by students with special needswith mentaldisabilities. Paying attention to the fact that the student population is quite large, it is necessary to be concerned with creating empowerment programs to encourage community involvement in order to help students with special needs in order to achieve independence. In general, students have a background of poor socio-economic conditions and need help from other parties to improve their living conditions. On the other hand, the empowerment program from the local government has notbeen ableto reachallexisting students, so they find it difficult to increase resources. The purpose of community service to students at SLB PSM is to help students with special needs in improving skills and welfare, with the following objectives: 1. Facilitating the availability of materials, equipment andfacilities needed as business capital; 2 . Skills training and production of goods that can be made by students with special needs; 3 . Ensuring the sustainability of businesses that have been initiated and developed; 4; Realizing business independence for students with special needs. Activities are carried out by pioneering and making various types of skills by utilizing ciprat batik cloths so that they can have artistic value, are economical andmarket-oriented, so that they can earn income to meet their daily needs.
\end{abstract}

Keywords: empowerment, students with specialneeds, independence

\begin{abstract}
Abstrak. Siswa di Sekolah Luar Biasa Pesantren Sabilil Muttaqien (SLB PSM) Ta keran Ka bu paten Magetan banyak didominasi oleh siswa berkebutuhan khusus tuna grahita. Memerhatik an fakta bahwa populasi siswa tersebut cukup banyak, perlu kepedulian dengan membuat program pemberdaya an un uk mendorong keterlibatan masyarakat agar membantu siswa berkebutuhan khusus agar bis a mewujudkan kemandirian. Secara umum, para siswa memiliki la tar belakang kond isi sosia l ek on omi miskin dan membutuhkan bantuan dari pihak lain untuk meningk atkan kondisi kehidupannya. Di sisi lain, progra m pemberdayaan dari pemerintah daerah juga belum mampu menjangkau seluruh siswa yang ada, sehingga mereka kesulitan untuk meningkatkan sumber daya. Tujuan pengabdian masyarakat pada sis wa di SLB PSM adalah membantu siswa berkebutuhan khusus dalam meningkatkan keterampilan dan ke sejahteraan, dengan tujuan: 1. Memfasilitasi ketersediaan bahan, peralatan serta sarana y ang dibutuhkan sebagai modal u saha; 2 . Pela tihan keterampilan dan produksi barang yang mampu dibuat oleh siswa berkebutuhan khusus; 3 . Menjamin keberlanjutan usaha yang tela $\mathrm{h}$ dirin tis dan dikembangkan; 4; Mewujudkan kemandirian usaha bagi siswa berkebutuhan khusus. Kegiatan dilaksanakan dengan cara merin tis da $n$ membuat aneka jenis keterampilan dengan memanfaatkan perca kain batik ciprat agar bisa memiliki nila i seni, ekonomis dan berorientasi pasar, sehingga memeroleh pendapatan guna memenuhi kebutuhan hidupnya.
\end{abstract}

Kata kunci : pemberdayaan, siswa berkebutuhan khusus, kemandirian

\section{PENDAHULUAN}

Anak berkebutuhan khusus adalah seseorang yang memiliki keterbatasan fisik, mental, intelektual, atau sensorik dalam jangka waktu yang lama. Pemerintah Indonesia telah meratifikasi Convention On The Rights Of Persons With Disabillities, selanjutanya disebut
CPRD yang diatur dalam Undang-undang No 19 Tahun 2011. Ratifikasi CPRD menunjukkan adanya komitmen Pemerintah untuk melindungi, memajukan, dan memenuhi hak anak berkebutuhan khususyang pada akhirnya akan mampu mewujudkan kemandirian dan 
kesejahteraan bagi anak berkebutuhan khusus (Lestari, 2017).

Menurut Undang-Undang Nomor 8 tahun 2016, anak berkebutuhan khusus adalah setiap orang yang mengalami keterbatasan fisik, intelektual, mental, dan/atau sensorik dalam jangka waktu lama yang dalam berinteraksi dengan lingkungan dapat mengalami hambatan dan kesulitan untuk berpartisipasi secara penuh dan efektif dengan warga negara lainnya berdasarkan kesamaan hak. Upaya pemerintah untuk mewujudkan kemandirian dan kesejahteraan anak berkebutuhan khusus adalah dengan cara peningkatan kesejahteraan yang dilakukan melalui kesamaan kesempatan, rehabilitasi, bantuan sosial, dan pemeliharaan taraf kesejahteraan sosial. Hal ini sudah diatur dalam Peraturan Pemerintah Nomor 43 Tahun 1998 tentang Upaya Peningkatan Kesejahteraan Sosial Anak berkebutuhan khusus (Mulyati et al., 2019).

Permasalahan yang dialami oleh mitra sebagai pelaksana Sekolah Luar Biasa (SLB) PSM Takeran Kabupaten Magetan cukup komplek sehingga hanya sedikit masyarakat yang mempunyai ketertarikan dengan pendidikan dan orang tua masih enggan menyekolahkan anaknya yang memiliki kelainan khusus untuk disekolahkan di SLB. Hal ini disebabkan antara lain: (1) Keberadaan Sekolah Pendidikan Luar Biasa belum memenuhi fasilitas yang memadai; (2) Adanya anggapan negatif sebagian masyarakat sekitar bahwa Pendidikan Luar Biasa kurang efektif dibanding sekolah umum/normal dan (3) Kurangnya kesadaran orang tua / masyarakat untuk menyekolahkan anak yang berkelainan sehingga masih banyak orang tua yang menyembunyikan anaknya karena malu. Upaya yang dilakukan oleh Tim yang belum dilakukan oleh mitra adalah menghubungkan dengan stake holder yang memiliki kepedulian terhadap anak berkebutuhan khusus serta menyampaikan kepada Yayasan Perguruan Islam Pesantren Sabilil Muttaqien sebagai Penyelenggara Sekolah untuk memprioritaskan kebutuhan SLB dengan membangun jaringan kerja dengan Pemerintah c.q Ditjen Pendidikan Masyarakat dan Pendidikan Khusus.
Penyelenggaraan Pendidikan Luar Biasa akan berkembang dengan baik apabila didukung oleh mitra kerja yang baik yaitu komite sekolah, masyarakat serta instansi terkait. Sehubungan dengan hal tersebut Lembaga Pendidikan Luar Biasa PSM Takeran Magetan yang terdiri dari jenjang TK-LB, SD-LB, SMPLB dan SMA-LB dalam melaksanakan program sangat mengharapkan untuk mendapat dukungan dan kerjasama. Tim Pengabdian Masyarakat Universitas Merdeka Madiun hadir untuk membantu memberi solusi atas permasalahan yang dihadapi mitra.

Tujuan kegiatan pengabdian ini adalah untuk memberdayakan anak berkebutuhan khusus di SLB PSM Takeran Kabupaten Magetan dengan memberikan keterampilan sebagai upaya untuk membekali siswa agar bisa memiliki kegiatan ekonomi sehingga mampu mandiri. Pelaksanaan kegiatan pengabdian masyarakat ini dispesifikasikan pada upaya pemberdayaan siswa berkebutuhan khusus melalui peningkatan lifeskill berbasis potensi siswa. Tim pengabdian dari Universitas Merdeka Madiun berperan sebagai pendamping atau narasumber yang bersama-sama sekolah merencanakan, melaksanakan dan mengevaluasi program yang telah disusun.

Pemberdayaan adalah sebuah proses penyadaran masyarakat yang dilakukan secara transformatif, partisipatif dan berkesinambung an melalui peningkatan kemampuan dalam menangani berbagai persoalan dasar yang mereka hadapi untuk meningkatkan kondisi hidup sesuai dengan cita-cita yang diharapkan. Permasalahan utama yang dihadapi oleh anak berkebutuhan khusus adalah keterbatasan akses terhadap pelayanan pendidikan, pekerjaan, kesehatan, transportasi, dan partisipasi politik atau keadilan. Mereka sering menghadapi hambatan untuk berpartisipasi dalam setiap aspek kehidupan dalam masyarakat. Hambatan dapat terjadi dalam berbagai bentuk, termasuk dalam kaitan dengan lingkungan fisik, teknologi informasi dan komunikasi, legislasi dan kebijakan yang belum sepenuhnya berpihak, sikap masyarakat serta diskriminasi (Iffatus Sholehah, 2017).

Anak dengan kebutuhan khusus atau biasa dikenal dengan istilah 'ABK' adalah anak 
yang memiliki kondisi berbeda dengan anak-anak lain pada umumnya. Kondisi berbeda ini bisa ter jadi dalam hal: karakteristik mental, kemampuan fisik, kemampuan sensoris, kemampuan komunikasi (verbalnonverbal), ketahanan diri, kemampuan menghargai dan menikmati aktivitas dalam hidup. Salah satu upaya pemberdayaan pada anak berkebutuhan khusus adalah dengan menyelenggarakan pendidikan keterampilan sebagai bagian dalam upaya memandirikan mereka, serta mengoptimalkan potensi dan kreativitas. Dengan demikian bisa mengangkat derajat, yang di kalangan masyarakat sering dianggap hanya menyusahkan orang lain dan dipandang sebelah mata. Padahal sejatinya mereka mempunyai kemampuan, hanya faktor komunikasi yang kurang sinergis (Shaleh, 2018).

Istilah anak berkebutuhan khusus mungkin kurang akrab di sebagian masyarakat Indonesia berbeda dengan "Penyandang Cacat". Istilah ini banyak yang mengetahui atau sering digunakan di tengah masyarakat. Anak berkebutuhan khusus dapat diartikan individu yang mempunyai keterbatasan. Menurut The International Classification of Impairment, Disability and Handicap (Organization, 2017), ada tiga definisi berkaitan dengan kecacatan, yaitu impairment, disability, dan handicap. Impairment adalah kehilangan atau abnormalitas struktur atau fungsi psikologis, fisiologis atau anatomis. Disability adalah suatu keterbatasan atau kehilangan kemampuan (sebagai akibat impairment) untuk melakukan suatu kegiatan dengan cara atau dalam batas-batas yang dipandang normal bagi seorang manusia. Handicap adalah suatu kerugian bagi individu tertentu, sebagai akibat dari suatu impairment atau disability, yang membatasi atau menghambat terlaksananya suatu peran yang normal. Namun hal ini juga tergantung pada usia, jenis kelamin, dan faktor-faktor sosial atau budaya. Undang-Undang RI Nomor 4 Tahun 1997 tentang Penyandang Cacat, Pasal 1 Ayat 1, mendefinisikan "penyandang cacat" sebagai "setiap orang yang mempunyai kelainan fisik atau mental, yang dapat mengganggu atau merupakan rintangan dan hambatan baginya untuk melakukan kegiatan secara selayaknya (Hayati \& Surya, 2020).
Masih rendahnya pemerataan pendidikan dan kualitas produk pendidikan adalah salah satu dari butir permasalahan pokok dalam pengembangan pendidikan khususnya Pendidikan Luar Biasa. Penyelenggaraan Pendidikan Luar Biasa Swasta merupakan upaya mengatasi permasalahan tersebut yaitu pemerataan pendidikan dengan prisip "Pendidikan Untuk Semua". Upaya peningkatan Sumber Daya Manusia ( SDM) terus menerus dilakukan oleh Pemerintah melalui dunia pendidikan. Hal ini merupakan perwujudan upaya memerbaiki mutu SDM bangsa dalam menghadapi persaingan ketat di era globalisasi.

Beberapa aspek keterampilan sosial diharapkan dimiliki oleh siswa berkebutuhan khusus yaitu: (1) Cooperation, kerja sama yang baik dapat membuktikan terjalinnya interaksi yang baik antara siswa normal dengan anak berkebutuhan khusus; (2) Assertion/ relasi, menjadi aspek dari keterampilan sosial, sebab kemampuan seseorang menjalin relasi dengan orang lain dinilai sebagai kemampuan berinteraksi; (3) Responsibility, tanggung jawab adalah perwujudan kesadaran akan kewajiban; (4) Empathy (empati), membuktikan seseorang memaknai peristiwa-peristiwa yang terjadi di lingkungan sosialnya dan (5) Self-control (kontrol diri) adalah kemampuan seseorang mengontrol emosi sehingga tidak larut dalam permasalahan sosial. (Syafi'ie, 2014).

\section{METODE PELAKSANAAN}

Kegiatan yang ditujukan kepada siswa berkebutuhan khusus di SLB PSM Takeran Magetan dilaksanakan selama 3 (tiga) hari mulai tanggal 27 hingga 29 Agustus 2020 mulai pukul 08.00 WIB hingga pukul 12.00 WIB. Tujuannya adalah untuk mengimplementasikan solusi yang ditawarkan terhadap permasalahan yang telah diuraikan, dengan memberikan keterampilan sebagai upaya untuk membekali siswa agar bisa memiliki kegiatan ekonomi sehingga mampu mandiri mencakup metode-metode sebagai berikut: 
Tabel 1. Jadwal Pelaksanaan Kegiatan

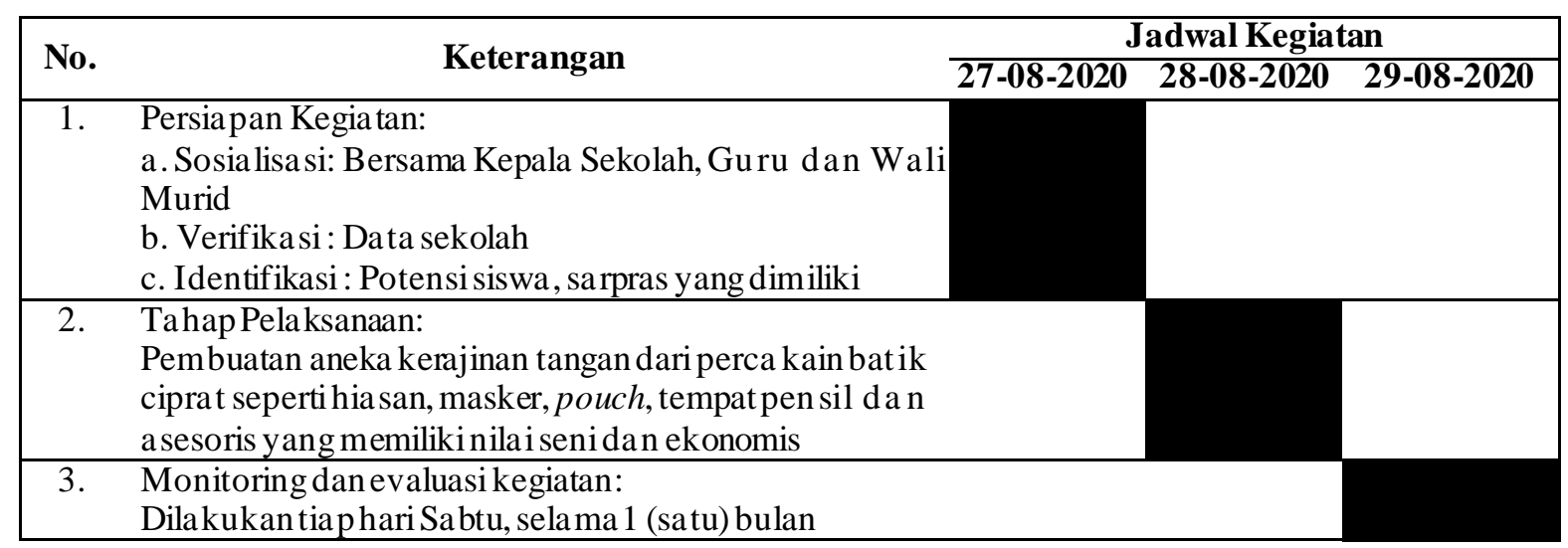

Keterangan:

\section{Persiapan Kegiatan}

Sosialisasi, verifikasi dan identifikasi sasaran yang bertujuan untuk mensosialisasikan program, mengetahui jumlah dan data lengkap (by name dan by address) siswa berkebutuhan khusus intelektual, mengetahui masalah, kebutuhan dan potensi siswa serta partisipan yang dapat mendukung kegiatan. Sosialisasi, verifikasi dan identifikasi sasaran dilaksanakan dengan:

a) Mengadakan pertemuan dengan Kepala Sekolah, Guru, Wali Murid untuk mensosialisasikan program;

b) Melakukan klarifikasi dan verifikasi data dan melengkapi data yang diperlukan melalui kunjungan langsung ke sekolah;

c) Mengidentifikasi potensi/ sumber daya siswa, kelembagan, finansial maupun sarana dan prasarana yang dapat dimanfaatkan;

2. Tahap Pelaksanaan

Dengan selalu menerapkan protocol kesehatan, kegiatan ini dilaksanakan dengan merintis dan mengembangan aneka jenis keterampilan/ usaha yang bernilai ekonomis dan berorientasi pasar. Meningkatkan dan melatih keterampilan dengan tujuan menyediakan kesempatan kerja bagi siswa berkebutuhan khusus melalui berbagai usaha/produksi barang, sehingga memeroleh pendapatan guna memenuhi kebutuhan hidupnya. Bahan yang digunakan adalah perca batik ciprat yang diperoleh dari KSM Sambung Roso Simbatan - Magetan, spons, kain fanel dengan peralatan yang digunakan adalah gunting, jarum, lem dan kertas.

3. Evaluasi

Monitoring dan evaluasi dilakukan dengan cara memberikan bimbingan teknis kepada Kepala Sekolah, guru dan wali murid dalam melakukan kegiatan pelayanan kepada siswa berkebutuhan khusus. Secara berkala, setiap minggu sekali selama masa pengabdian diadakan pertemuan untuk mengevaluasi kegitan yang telah dilaksanakan dan perkembangan hasil-hasil yang telah dicapai.

Dengan membantu meningkatkan kreatifitas, kesejahteraan dan kemandirian diharapkan memberi energi positif, semangat dan kepercayaan diri anak berkebutuhan khusus dalam melanjutkan kehidupan. Menurut (Mangunsong, 2009) anak berkebutuhan khusus atau anak luar biasa adalah anak yang mempunyai perbedaan dalam hal: ciri-ciri mental, kemampuan-kemampuan sensorik, fisik dan neuromaskular, perilaku sosial dan emosional, kemampuan berkomunikasi, maupun campuran dari dua atau lebih hal-hal di atas dari rata-rata anak normal; yang bersangkutan memerlukan perubahan yang mengarah pada perbaikan tugas-tugas sekolah, metode belajar atau pelayanan lainnya, yang bertujuan untuk mengembangkan potensi atau kemampuannya secara maksimal.

\section{HASIL DAN PEMBAHASAN}

Sekolah Luar Biasa Pesantren Sabilil Muttaqien (SLB PSM) memiliki latar belakang kondisi sosial ekonomi kurang mampu serta membutuhkan bantuan dari pihak lain untuk 
meningkatkan kondisi kehidupannya. Di sisi lain, program pemberdayaan dari pemerintah daerah juga belum mampu menjangkau seluruh anak berkebutuhan khusus yang ada, sehingga mereka semakin kesulitan untuk mengakses berbagai program pemerintah dan meningkatkan sumberdaya untuk menunjang kelangsungan hidup mereka. Dengan bantuan keterampilan mereka akan mampu menjadi insan mandiri dan dapat berkontribusi dalam bermasyarakat dan bernegara.

SLB PSM beralamat di Jalan Raya Takeran Kecamatan Takeran Kabupaten Magetan, didirikan pada tanggal 02 Juli 1992 oleh Yayasan Pendidikan Islam Pesantren Sabilil Muttaqien (YPI PSM), memiliki 11 (sebelas) guru pendamping, terdiri dari 4 (empat) orang ASN dan 7 (tujuh) orang guru Yayasan. Saat ini sebagai kepala sekolah adalah Tarbiyatuttammi, S.Pd.,M.M.Pd., memiliki siswa sebanyak 62 orang dengan tuna rungu sebanyak 12 orang, tuna daksa 1 orang, tuna netra 1 orang dan tuna grahita sebanyak 47 orang yang berasal dari Kecamatan Takeran, Bendo, Lembeyan,
Kawedanan dan Nguntoronadi Kabupaten Magetan. Gedung sekolah berstatus milik Yayasan.

Visi sekolah adalah terwujudnya pemenuhan hak asasi anak yang berkelainan menjadi manusia yang sehat, mandiri, beriman dan bertakwa kepada Allah SWT. Adapun misi sekolah adalah

a. Meningkatkan peran serta Komite Sekolah dalam upaya peningkatan mutu sekolah;

b. Meningkatkan upaya pemerataan kesempatan memeroleh pendidikan bagi anak yang berkelainan;

c. Melaksanakan manajemen sekolah yang memadai;

d. Mengondisikan sekolah yang sehat, indah, nyaman dan kekeluargaan;

e. Meningkatkan peran serta masyarakat dalam upaya pengembangan sekolah.

Jenjang pendidikan dan jumlah siswa disajikan pada Tabel 2. Jumlah siswa aktif SLB PSM Takeran-Magetan tahun 2020/2021 berdasarkan asal kecamatan dan kekurangan disajikan pada Tabel 3 .

Tabel 2. Jenjang Pendidikan Siswa SLB Tahun 2020/2021

\begin{tabular}{clccc}
\hline \multirow{2}{*}{ No. } & \multirow{2}{*}{ Jenjang Pendidikan } & \multicolumn{2}{c}{ Jenis Kelamin } & \multirow{2}{*}{ Jumlah } \\
\cline { 2 - 4 } & & Laki-laki & Perempuan & \\
\hline 1. & TK-LB & 1 & - & 1 \\
\hline 2. & SD-LB & 23 & 13 & 36 \\
\hline 3. & SMP-LB & 13 & 4 & 17 \\
\hline 4. & SMA-LB & 5 & 3 & 8 \\
\hline Jumlah & 42 & 20 & 62 \\
\hline
\end{tabular}

Sumber: SLB PSM Takeran-Magetan, Tahun 2020

Tabel 3. Jumlah Siswa Aktif Tahun 2019/2020

\begin{tabular}{|c|c|c|c|c|c|c|c|c|}
\hline \multirow{2}{*}{ No. } & \multirow{2}{*}{ Kecamatan Asal } & \multicolumn{2}{|c|}{ Jenis Kelamin } & \multicolumn{4}{|c|}{ Jenis Kecacatan : Tuna } & \multirow{2}{*}{ Total } \\
\hline & & $\mathbf{L}$ & $\mathbf{P}$ & Rungu & Netra & $\overline{\text { Daksa }}$ & Grahita & \\
\hline 1. & Takeran & 24 & 11 & 8 & - & 1 & 26 & 35 \\
\hline 2. & Nguntoronadi & 12 & 5 & 2 & - & - & 15 & 17 \\
\hline 3. & Kawedanan & - & 1 & - & - & - & 1 & 1 \\
\hline 4. & Lembeyan & 1 & - & 1 & - & - & - & 1 \\
\hline 5. & Bendo & 6 & 2 & 1 & 1 & - & 6 & 8 \\
\hline \multicolumn{2}{|c|}{ Jumlah } & $\overline{43}$ & 19 & 12 & 1 & $\mathbf{1}$ & 48 & 62 \\
\hline
\end{tabular}

Sumber: SLB PSM Takeran-Magetan, Tahun 2020

Siswa berkebutuhan khusus sering dianggap tidak mampu melakukan kegiatan dan hanya menjadi beban bagi keluarga dan masyarakat, dikarenakan keterbatasan gerak mereka. Hal ini menimbulkan masalah mental dan sosial bagi penderitanya. SLB PSM menampung dan mempunyai program terkait dengan memberikan bimbingan dan dukungan

agar mereka mampu menjalankan peran dan tugas kehidupannya sehingga tidak terjatuh dalam keadaan kondisi lemah dan terpinggirkan. Untuk mencapai target yang ditetapkan, lembaga mengadakan evaluasi diri secara obyektif dan sistematik dengan sembilan komponen yaitu :

1. Kurikulum dan proses pembelajaran 
a. Sekolah melaksanakan kurikulum Nasional dan kurikulum muatan lokal sesuai dengan ketentuan yang berlaku.

b. Sekolah memiliki kalender pendidikan dan jadwal pembelajaran yang jelas.

c. Proses pembelajaran

Guru melakukan perencanaan pembelajaran menggunakan berbagai variasi, strategi, pendekatan, metode pembelajaran.

2. Administrasi dan manajemen sekolah

a. Sekolah memiliki rencana yang akan dicapai dalam jangka panjang yang dijadikan acuan dalam rencana operasional. Visi dan misi dijadikan acuan dalam merumuskan tujuan sekolah dan hasil yang diharapkan. Kriteria utama mutu perencanaan sekolah adalah sejauh mana warga sekolah memahami dan menyadari visi, misi dan tujuan sekolah.

b. Manajemen sekolah menerapkan menajemen berbasis sekolah yang ditunjukkan dengan kemandirian, kemitraaan, partisipasi, semangat kebersamaan secara efektif dan efisien.

3. Organisasi dan kelembagaan

Sekolah memiliki organisasi dan pembagian kerja yang dinamis sesuai dengan arah tujuan sekolah.

4. Sarana Prasarana

Sekolah memiliki sarana dan prasarana yang meliputi: gedung sekolah, perabotan sekolah dan alat/ media pendidikan.

5. Tenaga Kependidikan dan Tenaga Penunjang a. Tenaga kependidikan

Sekolah memiliki tenaga kependidikan profesional yang jumlahnya memadai dengan kualifikasi kompetensi dan tingkat kesesuaian berdasarkan peraturan yang berlaku.

b. Tenaga Penunjang

Sekolah memiliki tenaga penunjang yang unsur- unsurnnya terkait dengan tugas pokok dan fungsinya meliputi tenaga administratif dan tenaga pendidikan yang profesional.

6. Pembiayaan / Pendanaan

a. Sekolah memiliki dana pendidikan yang cukup dan berkelanjutan untuk menyelenggarakan proses belajar mengajar yang bermutu disekolah.

b. Sekolah menghimpun dana dari berbagai potensi sumber dana dan mengelola dana secara transparan.

\section{Peserta Didik}

Penerimaan peserta didik didasarkan atas kriteria yang jelas, transparan dan akuntabel. Sekolah melakukan evaluasi kemajuan dan hasil belajar peserta didik dan menghasilkan lulusan yang memadai dalam prestasi akademik dan non akademik.

8. Peran Serta Masyarakat, Budaya dan Lingkungan Sekolah

Sekolah mengajarkan peserta didik tentang kecakapan yang diperlukan untuk menjalani kehidupan di masyarakat dan mendapat dukungan dari masyarakat yang berupa finansial dan moral.

Sekolah memiliki Komite sekolah yang memberi peluang pada masyarakat untuk berperan sebagai advisor, supporter, mediator dan controller.

Tim pengabdian masyarakat Universitas Merdeka Madiun bekerja sama dengan SLB PSM Takeran Magetan memberikan kegiatan pelatihan berupa kerajinan tangan dari perca batik ciprat seperti hiasan, masker, pouch, tempat pensil dan asesoris yang memiliki nilai seni dan ekonomis. Program tersebut dilaksanakan selama 1 minggu di sekolah, dimaksudkan untuk membantu siswa berkebutuhan khusus agar memiliki keterampilan dengan tujuan:

1. Memfasilitasi ketersediaan bahan, peralatan serta sarana yang dibutuhkan sebagai modal usaha siswa berkebutuhan khusus; dan

2. Mengupayakan keberlanjutan usaha yang telah dirintis dan dikembangkan.

Kegiatan keterampilan yang dilakukan bagi siswa berkebutuhan khusus di SLB PSM Kecamatan Takeran Magetan adalah:

1. Pembuatan aneka kerajinan dari perca batik ciprat seperti tempat pensil, masker, pouch, hiasan dan asesoris yang bernilai seni dan ekonomi;

2. Pembuatan aneka kerajinan tangan dari bermacam-macam wadah plastik bekas; dan Siswa yang mengikuti pelatihan sebanyak 20 (dua puluh) anak yang dipilih oleh guru pendamping sekolah berdasarkan prestasi dan 
mewakili masing-masing kelompok. Meskipun dilaksanakan di masa normal baru, proses kegiatan keterampilan tetap menerapkan protokol kesehatan dengan selalu memakai masker, menjaga jarak dan sering mencuci tangan di tempat yang telah disediakan pihak sekolah. Kegiatan pemberian keterampilan dilaksanakan selama 3 (tiga) hari mulai tanggal 27 sampai 29 Agustus 20202 dan siswa begitu semangat mengikuti kegiatan. Karya yang dihasilkan menjadi koleksi sekolah.

SLB PSM Takeran disarankan menjalin kerja sama dengan Kelompok Swadaya Masyarakat (KSM) Sambung Roso Simbatan Nguntoronadi Magetan yang mewadahi para penyandang disabilitas. Siswa yang telah menyelesaikan pendidikan di SLB PSM, supaya tetap produktif dan bisa mengimplementasikan keterampilannya, diarahkan ke KSM Sambung Roso untuk membuat batik ciprat dan produk turunannya atau dipekerjakan pada orang lain yang membutuhkan seperti penjahit, pengusaha konveksi atau melaksanakan kegiatan sendiri di rumah masing-masing sesuai bakat yang dimiliki.

\section{SIMPULAN DAN SARAN}

Berdasarkan hasil pengabdian disimpulkan bahwa:

(1) Sekolah mampu menerapkan konsep sekolah inklusi dengan cukup baik; (2) Sekolah telah memberikan pelayanan terhadap siswa berkebutuhan khusus; (3) Hak siswa cukup terpenuhi yakni: memeroleh perlakuan sesuai bakat, minat, kemampuan, dan kelainan, mengikuti program pendidikan, memeroleh bantuan fasilitas belajar, beasiswa, atau bantuan lain sesuai dengan kelainan yang disandang, memeroleh penilaian hasil belajar; dan (4) Pelaksanaan kegiatan pengabdian masyarakat berlangsung lancar dan mendapat respon positif dari pihak sekolah maupun siswa.

Saran yang diberikan oleh Tim pengabdian adalah:

(1) Sekolah perlu meningkatkan pelayanan dan fasilitas pendidikan; (2) Sumber daya manusia perlu terus ditingkatkan dengan mengikutsertakan pada workshop, pelatihan dan sejenisnya, sehingga dapat memberikan pelayanan maksimal terhadap siswa; (3) Pemberdayaan terhadap siswa berkebutuhan khusus hendaknya terus dilakukan, agar kemandirian mereka dapat diwujudkan; dan (4) Pihak sekolah hendaknya menyelenggarakan kegiatan produktif bagi siswa yang memberikan manfaat secara sosial, ekonomis, dapat meningkatkan kreativitas produk dan memiliki daya saing.

\section{UCAPAN TERIMAKASIH}

Ucapan terimakasih disampaikan kepada: (1) Yayasan Perguruan Tinggi Merdeka Madiun (YAPERTIMMA) yang telah membiayai program pengabdian masyarakat ini; dan (2) Kepala SLB PSM Takeran Magetan bersama dewan guru yang telah bersedia menjadi obyek pengabdian serta membantu pelaksanaan dan komunikasi antara Tim pengabdian dengan siswa berkebutuhan khusus.

\section{DAFTAR PUSTAKA}

Hayati, S., \& Surya, M. A. (2020). Peran Dinas Sosial Dalam Pemberdayaan Penyandang Disabilitas di Kota Binjai. Jurnal Pemberdayaan Masyarakat. https://doi.org/10.37064/jpm.v6i2.6893

Iffatus Sholehah. (n.d.). Pemberdayaan Difabel Melalui Asset Based Approach. Jurnal

Pemberdayaan Masyarakat: Media Pemikiran Dan Dakwah Pembangunan, 1(1).

Lestari, E. (2017). Pemenuhan Hak Bagi Penyandang Disabilitas di Kabupeten Semarang Melalui Implementasi Convention on the Rights of person with disabillities (CPRD) dalam Bidang Pendidikan. Integralistik.

Mangunsong, F. (2009). Psikologi dan Pendidikan Anak Berkebutuhan Khusus. Depok: Lembaga Pengembangan Sarana Pengukuran dan Pendidikan Psikologis (LPSP3) Fakultas Psikologi Universitas Indonesia (FPUI).

Mulyati, T., Rohmatiah, A., \& Amadi, D. N. (2019). Pelatihan Dan Pendampingan Penyandang Disabilitas Desa Simbatan, Kecamatan Nguntoronadi Kabupaten 
Magetan. Jurnal Terapan Abdimas, 4(2), 187. https://doi.org/10.25273/jta.v4i2.4844

Organization, I. L. (ILO). (2017). Inklusi Penyandang Disabilitas di Indonesia. Jurnal Refleksi Hukum.

Shaleh, I. (2018). Implementasi Pemenuhan Hak bagi Penyandang Disabilitas Ketenagakerjaan di Semarang. Kanun Jurnal
Ilmu

Hukum.

https://doi.org/10.24815/kanun.v20i1.9829

Syafi'ie, M. (2014). Pemenuhan Aksesibilitas

Bagi Penyandang Disabilitas. INKLUSI.

https://doi.org/10.14421/ijds.010208 